\title{
Streptococcus salivarius inhibits immune activation by periodontal disease pathogens
}

Kyle W. MacDonald ${ }^{1,2}$, Ryan M. Chanyi ${ }^{1,2}$, Jean M. Macklaim²,3, Peter A. Cadieux ${ }^{2,4}$, Gregor Reid ${ }^{1,2}$ and Jeremy P. Burton ${ }^{1,2,5^{*}}$ (1)

\begin{abstract}
Background: Periodontal disease represents a major health concern. The administration of beneficial microbes has been increasing in popularity over efforts to manipulate the microbes using antimicrobial agents. This study determined the ability of Streptococcus salivarius to inhibit IL- 6 and IL-8 production by gingival fibroblasts when activated by periodontal pathogens and their effect on the salivary microbiome.

Methods: Primary human gingival fibroblasts were challenged with Porphyromonas gingivalis, Aggregatibacter actinomycetemcomitans and Fusobacterium nucleatum and a combination of all three. IL-6 and IL-8 cytokine release were measured. Using this same model, S. salivarius K12, M18 and different supernatant and whole-cell lysate fractions of S. salivarius $\mathrm{K} 12$ were administered to pathogen-induced fibroblasts. A patient study of healthy participants was also conducted to determine the effect $\mathrm{S}$. salivarius $\mathrm{K} 12$ had on the native microbiome using $16 \mathrm{~S}$ next generation sequence analysis.
\end{abstract}

Results: All pathogens tested induced a significant IL-6 and IL-8 response. S. salivarius K12 or M18, did not exhibit an increase in inflammatory cytokines. When either of the probiotic strains were co-administered with a pathogen, there were significant reductions in both IL-6 and IL-8 release. This effect was also observed when gingival fibroblasts were pre-treated with either S. salivarius $\mathrm{K} 12$ or $\mathrm{M} 18$ and then stimulated with the oral pathogens. Chewing gum containing S. salivarius K12 did not alter the salivary microbiome and did not increase inflammatory markers in the oral cavity.

Conclusion: S. salivarius $\mathrm{K} 12$ and M18 prevented immune activation induced by periodontal disease pathogens. S. salivarius $\mathrm{K} 12$ did not alter the salivary microbiome or induce immune activation when administered as a chewing gum. These results warrant further study to determine if it may be an effective treatment in a model of periodontal disease.

Keywords: Streptococcus salivarius, Periodontal disease, Immune inhibition, Probiotics, Chewing gum, Porphyromonas gingivalis, Aggregatibacter actinomycetemcomitans, Fusobacterium nucleatum

\section{Background}

Periodontal disease is characterized by inflammation of the tissues that surround and support teeth, including the gingiva and periodontal ligaments. It is believed that

\footnotetext{
*Correspondence: jeremy.burton@lawsonresearch.com

${ }^{1}$ Department of Microbiology and Immunology, Schulich School

of Medicine and Dentistry, University of Western Ontario, London, ON,

Canada

Full list of author information is available at the end of the article
}

up to $50 \%$ of North American adults suffer from some form of periodontal disease, making it a major public health concern [1]. The oral cavity is abundant in microbial life, collectively referred to as the "oral microbiota". During disease, the oral microbiota shifts from a Grampositive-dominated community to one comprised mainly of Gram-negative bacteria [2]. Bacteria classically considered to be strongly associated with periodontal disease include Porphyromonas gingivalis, Aggregatibacter 
actinomycetemcomitans and Fusobacterium nucleatum [3]. These are anaerobic bacteria that trigger the release of pro-inflammatory cytokines, leading to immune cell recruitment, tissue destruction, and eventual bone loss. Cytokines important in this destructive cycle include IL-1 $\beta$ (bone resorption, metalloproteinase production), IL-6 (B-cell activation), IL-8 (attraction and activation of neutrophils), and TNF- $\alpha$ (bone resorption) [4].

Oral disease is the fourth most expensive disease to treat worldwide [5] and simple and accessible solutions are needed. Combined with the increase in antibiotic resistance, many novel therapeutic approaches are being developed to aid in oral health and minimizing the impact on the patient. One of these include the use of beneficial bacteria to defend the oral microbiota from a dysbiotic state and exacerbating disease. It is important that a treatment strategy maintains the integrity of the native microbiome without compromising it. Also, a treatment involving live bacteria should remain undetected from the immune system or risk worsening disease symptoms or decreasing treatment efficacy. There are several mechanisms of action by which probiotics exert a beneficial effect either directly or indirectly that may help in the oral cavity. The most useful in terms of protection from oral pathogens is through direct competition with another organism by the production of natural antimicrobial compounds, known as bacteriocins [6]. Other mechanisms enhancing immune regulation [7], improving the integrity of epithelial barriers and function of tight junctions $[8,9]$, and production of metabolites [10], enzymes, co-factors, and vitamins [11], all of which benefit the health of the host.

Probiotics designed to treat periodontal disease have been tested with promising results. Teughels et al. [16] examined the daily usage of lozenges containing Lactobacillus reuteri by patients suffering from chronic periodontitis following standard dental scaling and root planing. This treatment resulted in a significant reduction in pocket depth and attachment gain in deep periodontal pockets, as well as a decrease in $P$. gingivalis compared to those subjects who received a placebo lozenge. A similar study using Lactobacillus salivarius WB21-containing tablets demonstrated the ability of this bacterium to reduce the plaque index and periodontal pocket depth in subjects at high risk of periodontal disease [17]. The major metabolic end product of many of these potential probiotics is lactic acid which may have a negative impact on tooth decay over time. For the best result, a non-acid secreting, bacteriocin-producing, colonizer of the oral microbiota may be preferable. Streptococcus salivarius is a Gram-positive bacterium that colonizes the human oral cavity throughout the host's life and is generally associated with health [18]. S. salivarius K12 and M18 have in vitro inhibitory activity against another oral-pathogen, Streptococcus pyogenes [19]. Both strains encode multiple bacteriocins [20,21], are safe for human consumption [22-24], and can persist in the human oral cavity $[25,26]$, particularly on the tongue dorsum and other mucosal membranes. S. salivarius $\mathrm{K} 12$ has been shown in placebo-controlled studies to prevent recurrent streptococcal induced pharyngitis in adults [27] and children [28], as well as reduce halitosis by limiting the production of volatile sulphur compounds from anaerobic bacteria. S. salivarius M18 consumption was able to reduce dental plaque scores and the concentration of $S$. mutans in children [29].

As periodontal disease is primarily inflammation driven, and S. salivarius $\mathrm{K} 12$ and M18 have a proven record of safety and efficient colonization in the human oral cavity, we set out to characterize whether S. salivarius $\mathrm{K} 12$ or M18 can modulate inflammatory factors produced by human gingival fibroblasts exposed to common dental pathogens and in healthy volunteers, whether changes in the salivary microbiome or secreted cytokines resulted upon increased exposure to S. salivarius.

\section{Methods \\ Ethics approval}

The study was approved by the Health Sciences Research Ethics Board at The University of Western Ontario (REB 104641, 03/01/2014) and the Clinical Research Impact Committee at the Lawson Health Research Institute (R-13-523). Consent for publication was granted by all participants and any identifying information was removed.

\section{Cultures and growth conditions}

Strains used in this study are listed in Table 1. S. salivarius, S. mutans $25175, C$. albicans and the nine indicator strains (I1 to I9) were maintained on Brain Heart Infusion medium containing $0.6 \%(\mathrm{w} / \mathrm{v})$ yeast extract. $A$. actinomycetemcomitans, $P$. gingivalis, and $F$. nucleatum were grown anaerobically on Columbia Blood agar (CBA) containing $5 \%$ sheep's blood at $37^{\circ} \mathrm{C}$ in an anaerobic chamber containing $85 \%(\mathrm{v} / \mathrm{v}) \mathrm{N}_{2}, 10 \%(\mathrm{v} / \mathrm{v}) \mathrm{H}_{2}$ and $5 \%(\mathrm{v} / \mathrm{v}) \mathrm{CO}_{2}$. Lactobacillus strains were maintained in De Mann, Rogosa, Sharpe (MRS). When required, 1.5\% $(w / v)$ agar was used for propagation on plates.

\section{Primary human gingival fibroblasts}

Gingival fibroblasts were cultured from explanted tissue obtained from healthy volunteers undergoing periodontal procedures in the Oral Surgery Clinic (Western University, Canada) in accordance with the guidelines of the University's Research Ethics Board (REB 13937E) with informed patient consent. Periodontal fibroblasts were 
Table 1 Cultures used in this study

\begin{tabular}{|c|c|}
\hline Microorganism & Strain \\
\hline \multicolumn{2}{|l|}{ Yeast } \\
\hline Candida albicans & TIMM 1768 \\
\hline \multicolumn{2}{|l|}{ Bacteria } \\
\hline $\begin{array}{l}\text { Aggregatibacter actinomycetemcomi- } \\
\text { tans }\end{array}$ & Y4 (ATCC 43718) \\
\hline Porphyromonas gingivalis & ATCC 33277 \\
\hline Fusobacterium nucleatum & ATCC10593 \\
\hline Streptococcus mutans & ATCC25175 \\
\hline Streptococcus salivarius & $\mathrm{K} 12$ \\
\hline Streptococcus salivarius & M18 \\
\hline Lactobacillus reuteri & $\mathrm{RC}-14$ \\
\hline Lactobacillus plantarum & Lp-2001 \\
\hline Lactobacillus helveticus & LAFTI L-10 \\
\hline \multicolumn{2}{|l|}{ Bacterial indicator strains } \\
\hline Micrococcus luteus & I1 Courtesy of J.R. Tagg (Otago) \\
\hline Streptococcus pyogenes M-type 52 & 12 Courtesy of J.R. Tagg (Otago) \\
\hline Streptococcus constellatus & I3 Courtesy of J.R. Tagg (Otago) \\
\hline Streptococcus uberis & 14 Courtesy of J.R. Tagg (Otago) \\
\hline Streptococcus pyogenes M-type 4 & I5 Courtesy of J.R. Tagg (Otago) \\
\hline Lactococcus lactis ssp. lactis & 16 Courtesy of J.R. Tagg (Otago) \\
\hline Streptococcus pyogenes M-type 87 & I8 Courtesy of J.R. Tagg (Otago) \\
\hline Streptococcus dysgalactiae & 19 Courtesy of J.R. Tagg (Otago) \\
\hline
\end{tabular}

isolated from four patients and were routinely cultured in minimum essential medium (MEM) supplemented with $10 \%(\mathrm{v} / \mathrm{v})$ fetal bovine serum and $100 \mathrm{mM} \mathrm{L}$-glutamine in a humidified incubator at $37{ }^{\circ} \mathrm{C}$ and $5 \% \mathrm{CO}_{2}$. Experiments were carried out on the gingival fibroblasts between passages 4 to 9 . Fibroblasts were inoculated $\left(5 \times 10^{5}\right.$ cells $)$ in a 24-well plate with $500 \mu \mathrm{l}$ MEM supplemented medium and grown for $48 \mathrm{~h}$ to reach confluency.

\section{Simultaneous bacterial antagonism}

Simultaneous bacterial antagonism assays were conducted as previously described [19]. Briefly, overnight cultures of the indicator strains or pathogens of interest (Table 1 ) were evenly spread over the surface of a CBA plate. Individual colonies of S. salivarius $\mathrm{K} 12$ and M18 were used to stab-inoculate the CBA plate and incubated for $48 \mathrm{~h}$ at $37{ }^{\circ} \mathrm{C}$ in $5 \% \mathrm{CO}_{2}$. Zones of inhibition surrounding the stab inoculum were used to assess the direct antagonistic effect the bacteria had on pathogen growth.

\section{Deferred bacterial antagonism}

A single colony of S. salivarius K12 or M18 was used to inoculate a $1 \mathrm{~cm}$ wide streak on a CBA plate and incubated at $37{ }^{\circ} \mathrm{C}$ in $5 \% \mathrm{CO}_{2}$ for $18 \mathrm{~h}$. The bacterial growth was removed from the plate using a sterile cotton swab then sterilized by chloroform vapour for $20 \mathrm{~min}$. After drying, the indicator strains and pathogens were inoculated onto the plate as a perpendicular line to previous growth. The plate was further incubated for at $37{ }^{\circ} \mathrm{C}$ in $5 \% \mathrm{CO}_{2}$ for $48 \mathrm{~h}$. Since only the secreted by-products from the probiotic bacteria remained, any inhibitory activity to pathogen growth can be attributed to a metabolite secreted during normal growth and not stimulated through direct competition.

\section{Co-aggregation to periodontal pathogens}

Overnight cultures of each bacterial strain were centrifuged at $3000 \mathrm{~g}$ for $10 \mathrm{~min}$ and washed 3 times in sterile PBS. Cultures were resuspended in a final volume of PBS to achieve an optical density $\left(\mathrm{OD}_{600}\right)$ of 1.0. Each pathogen was mixed in equal parts with either $S$. salivarius K12 or M18. The turbidity of the cultures were recorded after $8 \mathrm{~h}$ together and compared to the individual culture alone. $C$. albicans and $S$. mutans were used as positive and negative controls, respectively, based on well-known coaggregation abilities. Cultures were given a score based on observed aggregation.

\section{S. salivarius attachment to primary human gingival fibroblasts}

Primary human gingival fibroblasts were processed as described above. Overnight cultures of $S$. salivarius K12 and M18 were centrifuged at $3000 \times g$ for $10 \mathrm{~min}$ and resuspended in the same volume of phosphate buffered saline. This was repeated three times to remove residual bacterial media. S. salivarius K12 and M18 were resuspended in supplemented MEM and added to the gingival fibroblasts at a multiplicity of infection (MOI) of 25:1 and incubated for $8 \mathrm{~h}$ at $37{ }^{\circ} \mathrm{C}$ in $5 \% \mathrm{CO}_{2}$. The monolayers were washed three times with sterile PBS to remove nonadherent bacteria. Triton X-100 $(0.1 \% \mathrm{v} / \mathrm{v})$ was added to lyse the fibroblasts, releasing adherent $S$. salivarius K12. Bacterial CFUs were determined using dilution plating on CBA. Plates were incubated at $37{ }^{\circ} \mathrm{C}$ in $5 \% \mathrm{CO}_{2}$ overnight.

\section{Gingival fibroblast challenge and cytokine analysis}

Anti-inflammatory effects of S. salivarius K12 and M18 were examined using a gingival fibroblast challenge model. Fibroblasts were prepared in 24-well plates as explained above. S. salivarius, pathogen or a combination were added to the fibroblasts at a MOI of 25:1. Bacteria were co-incubated with the fibroblasts for $8 \mathrm{~h}$ after which the culture supernatant was collected, briefly centrifuged to remove larger debris, and stored at $-20{ }^{\circ} \mathrm{C}$ for further analysis. Similarly, to examine the effect of pre-treatment with S. salivarius strains, either S. salivarius K12 or M18 were applied to gingival fibroblasts $30 \mathrm{~min}$ prior to the 
addition of the periodontal pathogens. This was then further incubated for $8 \mathrm{~h}$, the supernatant collected, briefly centrifuged and stored at $-20{ }^{\circ} \mathrm{C}$ until further analysed. In all samples, the concentration of IL- 6 and IL-8 were determined using a multiplex immunoassay kit (Luminex).

\section{Supernatant analysis}

To determine whether S. salivarius K12 produced any soluble anti-inflammatory factors, it was grown overnight at $37{ }^{\circ} \mathrm{C}$, centrifuged, and the resultant supernatant was $0.22 \mu \mathrm{m}$ filter-sterilized, then applied to F. nucleatum stimulated fibroblasts for $8 \mathrm{~h}$. For further analysis, $S$. salivarius $\mathrm{K} 12$ supernatant was fractionated using a $10 \mathrm{kDa}$ (Centricon ${ }^{\circledR}$ Plus-70), with both the $<10 \mathrm{kDa}$ fraction and $>10 \mathrm{kDa}$ tested on stimulated fibroblasts.

\section{Preparation of freeze/thaw extract}

To assess the production of intracellular compounds produced by $S$. salivarius K12 that may inhibit immune activation of gingival fibroblasts by $F$. nucleatum, a freeze thaw extract from a bacterial lawn of S. salivarius K12 was prepared. A lawn of $S$. salivarius $\mathrm{K} 12$ was grown on CBA for $48 \mathrm{~h}$ at $37^{\circ} \mathrm{C}$ in $5 \% \mathrm{CO}_{2}$. The plate was placed at $-80{ }^{\circ} \mathrm{C}$ for $4 \mathrm{~h}$, thawed at room temperature, and the resulting liquid was collected from the degraded matrix. This was $0.22 \mu \mathrm{m}$ filter sterilized. Additionally, fractions of this freeze thaw extract were subjected to heat treatment at $80{ }^{\circ} \mathrm{C}$ for $10 \mathrm{~min}$ or digested for $10 \mathrm{~min}$ using $0.05 \%$ trypsin at $37{ }^{\circ} \mathrm{C}$ with $5 \% \mathrm{CO}_{2}$. These fractions were added to $F$. nucleatum and were co-incubated to stimulate fibroblasts for $8 \mathrm{~h}$ and IL-8 was measured as described above.

\section{Probiotic gum study design}

Participants were recruited between the ages of 20-60 years with general good oral health. Participants were excluded if they had any oral disease, an oral implanted device, were currently taking antibiotics, or had a dental appointment scheduled during the course of the study. A total of twenty healthy adult volunteers were selected and assigned to two study groups $(n=10)$, matched for age and sex. Participants received either chewing gum containing S. salivarius K12 (CulturedCare $^{\mathrm{TM}}$ with BLIS K12 ${ }^{\mathrm{TM}}$; Group 1) or regular gum tablets lacking S. salivarius K12 (Group 2). Each individual was assigned a unique identifier code, to ensure anonymity and that we would be blinded to which group a sample belonged too. Both gum types were similar in taste, appearance, and texture. Participants were supplied enough gum tablets to last the duration of the study. Additional file 1: Figure S1 demonstrates the overview of the study design. A $3 \mathrm{~mL}$ sample of unstimulated saliva was collected at appropriate time points for 7 days followed by a further 7 day wash out period. Samples were stored at $-80^{\circ} \mathrm{C}$ until all samples were received from all participants. One participant was not able to provide all samples and was excluded from analysis.

\section{In vivo cytokine release}

IL-1 $\beta$, IL-6, IL-8, and TNF- $\alpha$ were measured in saliva samples using multiplexed immunoassay as described above according to the manufacturer's instructions (Bio-Rad Laboratories Inc., Hercules, CA). A Bio-Plex 200 readout system was used (Bio-Rad), that utilizes Lumine ${ }^{\circledR}$ xMAP fluorescent bead-based technology (Luminex Corporation, Austin, TX).

\section{Salivary microbiome analysis}

DNA was extracted from saliva samples using the DNeasy PowerSoil 96-well Isolation Kit (Qiagen). The extraction was carried out as per the manufacturers protocol, with two changes; the addition of a $10 \mathrm{~min}$ incubation step at $65^{\circ} \mathrm{C}$ in a bead bath prior to the bead-beating step, and the centrifugation times for each step were doubled. In total, $500 \mu \mathrm{l}$ of saliva was used for the extraction of 94 samples. Extracted samples were amplified by PCR for the V4 region of the $16 \mathrm{~S}$ rRNA gene using barcoded primers as follows: V4L (forward) 5' GTGCCAGC[CA] GCCGCGGTAA 3' and V4R (reverse) 5' GGACTA C[ATC][ACG]GGGT[AT]TCTAAT 3'. Amplification was carried out in a $42 \mu \mathrm{L}$ reaction with $10 \mu \mathrm{L}$ of each primer (3.2 $\mathrm{pMol} / \mu \mathrm{L}$ stock), $20 \mu \mathrm{L}$ GoTaq hot start master mix (Promega) and $2 \mu \mathrm{L}$ extracted DNA. Thermocycling conditions were as follows: initial hot start activation at $95^{\circ} \mathrm{C}$ for $2 \mathrm{~min}$, then 25 cycles of $1 \mathrm{~min}$ at $95^{\circ} \mathrm{C}$ for denaturation, $1 \mathrm{~min} 55^{\circ} \mathrm{C}$ for primer annealing, and $1 \mathrm{~min}$ at $72{ }^{\circ} \mathrm{C}$ for extension. PCR products were quantified with a Qubit 2.0 fluorimeter and high sensitivity dsDNA specific fluorescent probes (Life Technologies). Samples were mixed at equimolar concentrations and purified with the QIAquick PCR Purification kit (Qiagen). The pooled product was sent to the London Regional Genomics Centre (Robarts Research Institute, Western University, London, Canada) for sequencing on the Illumina MiSeq platform using the 600-cycle kit to produce $2 \times 300$ paired-end reads. Using in-house Perl and Shell scripts, reads were retained if sequence matched the primer while allowing $2 \mathrm{bp}$ mismatches, and with perfect matches to expected sequence barcodes. Paired reads passing this filter were overlapped using pandaseq (https://github.com/neufeld/pandaseq) to produce fulllength V4 sequences assigned by sample. Operational taxonomic units (OTUs) were constructed by clustering V4 reads at 97\% sequence identity using USearch v. 7 (http://www.drive5.com/usearch/). OTUs were retained 
if they represented at least $0.1 \%$ relative abundance of any one sample. The most abundant sequence in the cluster was used as the reference sequence for taxonomic classification. The reference OTU sequences were compared to the ribosomal database project v11.2 (RDP; https:// rdp.cme.msu.edu) using Seqmatch v.3, and the lowest common taxonomy was retained out of the top 20 hits with an S_ab score $\geq 0.5$. OTU sequences from differential taxonomic groups were further validated by BLAST against the Human Oral Microbiome Database (HOMD) v. 13.2 (http://www.homd.org). The OTU table with assigned taxonomies was imported into QIIME (http:// qiime.org) for exploratory analyses including summarizing reads to different taxonomic levels, generating beta diversity with weighted UniFrac distance based on OTU sequence alignment with MUSCLE, and principal coordinate analysis (PCoA). Bar, stripchart, and PCoA plots were generated using $\mathrm{R}$.

\section{Statistical analysis}

Experiments were minimally performed in triplicate. Data was analysed using GraphPad Prism (Version 9.0.0 for Windows, GraphPad Software, San Diego, California, USA) using a one- or two-way ANOVA where appropriate with either the Dunnett's or Tukey's post-hoc multiple comparison test as described in the figure legend. Dunnett's post-hoc test was chosen when comparing multiple groups to a control group. Tukey's post-hoc test was chosen when comparing multiple groups to each other. For microbiome analysis, between-group comparisons for differential microbiota analyses were conducted with ALDEx2 package (http://www.bioconductor.org/packa ges/release/bioc/html/ALDEx2.html) in R. Taxonomic clusters were considered differential between groups with an adjusted $p$-value $<0.01$ using Welch's t-test with Benjamini-Hochberg multiple test correction, and with an effect size $\geq 1.5$.

\section{Results}

\section{S. salivarius interaction with oral pathogens}

Based on previous literature, it was confirmed that both S. salivarius $\mathrm{K} 12$ and M18 showed strong direct- and deferred-inhibition to all 9 indicator strains (Table 2), giving it P-Type 7-7-7. Upon an extended spectrum analysis, neither strain K12 nor M18 were able to inhibit C. albicans, S. mutans, P. gingivalis, F. nucleatum, nor A. actinomycetemcomitans via direct- and deferredantagonism assays (Table 2). A coaggregation assay demonstrated that both $\mathrm{K} 12$ and M18 were able to coaggregate moderately with $P$. gingivalis and $F$. nucleatum and weakly with $A$. actinomycetemcomitans (Table 3). No co-aggregation was observed with either strain and $S$. mutans (Table 3).
Table 2 Simultaneous and deferred bacterial antagonism

\begin{tabular}{|c|c|c|c|c|}
\hline \multirow[t]{2}{*}{ Indicator Strain } & \multicolumn{2}{|c|}{$\begin{array}{l}\text { Simultaneous } \\
\text { antagonism } \\
\text { S. salivarius } \\
\text { producer } \\
\text { strain }\end{array}$} & \multicolumn{2}{|c|}{$\begin{array}{l}\text { Deferred } \\
\text { antagonism } \\
\text { S. salivarius } \\
\text { producer } \\
\text { strain }\end{array}$} \\
\hline & $\mathrm{K} 12^{\dagger}$ & M18 & $\mathrm{K} 12$ & M18 \\
\hline Porphyromonas gingivalis ATCC 33277 & $-\S$ & - & - & - \\
\hline Fusobacterium nucleatum ATCC10593 & - & - & - & - \\
\hline $\begin{array}{l}\text { Aggregatibacter actinomycetemcomitans } \\
\text { Y4 }\end{array}$ & - & - & - & - \\
\hline Streptococcus mutans ATCC25175 & - & - & - & - \\
\hline Candida albicans TIMM 1768 & - & - & - & - \\
\hline Micrococcus luteus (I1) & $++^{n}$ & ++ & ++ & ++ \\
\hline Streptococcus pyogenes M-type 52 (12) & ++ & ++ & ++ & ++ \\
\hline Streptococcus constellatus (I3) & ++ & ++ & ++ & ++ \\
\hline Streptococcus uberis (14) & ++ & ++ & ++ & ++ \\
\hline Streptococcus pyogenes M-type 4 (15) & ++ & ++ & ++ & ++ \\
\hline Lactococcus lactis ssp. lactis (16) & ++ & ++ & ++ & ++ \\
\hline Streptococcus pyogenes M-type 28 (17) & ++ & ++ & ++ & ++ \\
\hline Streptococcus pyogenes M-type 87 (18) & ++ & ++ & ++ & ++ \\
\hline Streptococcus dysgalactiae (19) & ++ & ++ & ++ & ++ \\
\hline
\end{tabular}

Inhibition of bacterial growth by S. salivarius K12 or M18. Results were consistent across the three experiments conducted

${ }^{\dagger}$ Streptococcus salivarius K12; ${ }^{\ddagger}$ Streptococcus salivarius M18; ${ }^{\S}(-)$ No inhibition; ${ }^{9}(++)$ Strong inhibition

Table 3 Bacterial co-aggregation

\begin{tabular}{|c|c|c|c|c|}
\hline \multirow{2}{*}{$\begin{array}{l}\text { S. } \\
\text { salivarius } \\
\text { strain }\end{array}$} & \multicolumn{4}{|l|}{ Pathogen } \\
\hline & $\begin{array}{l}P . \\
\text { gingivalis }\end{array}$ & $\begin{array}{l}F . \\
\text { nucleatum }\end{array}$ & $\begin{array}{l}\text { A. } \\
\text { actinomycetemcomitans }\end{array}$ & S. mutans \\
\hline $\mathrm{K} 12^{\dagger}$ & $++^{\S}$ & ++ & + & $-"$ \\
\hline$M 18^{\ddagger}$ & ++ & ++ & + & - \\
\hline
\end{tabular}

Ability of S. salivarius K12/M18 to co-aggregate in solution with various pathogens. Results were consistent across the three experiments conducted ${ }^{\dagger}$ S. salivarius K12; ${ }^{\ddagger}$ S. salivarius $\mathrm{M} 18 ;{ }^{\S}(++)$ Moderate precipitation with evenly turbid supernatant and evidence of flocculation; ${ }^{n}(-)$ No co-aggregation, evenly turbid suspension

\section{Primary human gingival fibroblast challenge}

Both S. salivarius K12 and M18 were able to adhere to the primary human gingival fibroblasts at a ratio of 30 bacterial cells per fibroblast with no appreciable difference observed between them (Fig. 1). As a comparison, a widely used probiotic $L$. reuteri $\mathrm{RC}-14$, adhered at a ratio of 5 bacterial cells per fibroblast (Additional file 2: Fig. S2). Therefore, it was sought to determine if the ability of K12 and M18 to co-aggregate with oral pathogens would negatively impact the inflammatory response of the oral cavity. 


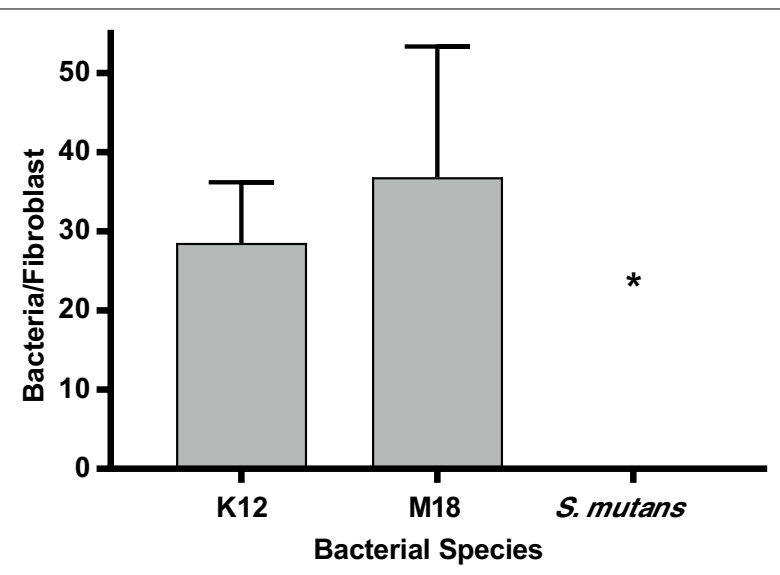

Fig. 1 Bacterial adherence to human gingival fibroblasts. Bacterial attachment to primary human gingival fibroblasts in vitro following 8 h co-incubation. S. salivarius K12 (K12); S. salivarius M18 (M18); S. mutans ATCC25175. Assay was carried out in triplet on three separate occasions. Samples were analysed using a one-way ANOVA with Dunnett's multiple comparison test with K12 as the control $\left({ }^{*} p<0.05\right.$ compared to K12 attachment). Error bars represent \pm standard error of the mean

Baseline IL- 6 and IL- 8 concentrations from unstimulated gingival fibroblasts were $330.3 \mathrm{pg} / \mathrm{ml}$ and $149.1 \mathrm{pg} / \mathrm{ml}$, respectively (Fig. 2). All three periodontal pathogens tested significantly increased the release of IL-6 (Fig. 2a) and IL-8 (Fig. 2b). P. gingivalis significantly activated the greatest IL-6 $(3333.9 \mathrm{pg} / \mathrm{ml}$; $p<0.001)$ and IL-8 release $(6812.5 \mathrm{pg} / \mathrm{ml} ; p<0.001)$ from gingival fibroblasts, followed by $F$. nucleatum (IL-6 = 2382.4 pg/ml, $p=0.0009 ; \quad$ IL-8 $=4251.8 \mathrm{pg} /$ $\mathrm{ml} ; p=0.005)$ and lastly, $A$. actinomycetemcomitans (IL-6 $=1551 \mathrm{pg} / \mathrm{ml}$; NS at $p=0.0595$; IL-8 $=2225.3 \mathrm{pg}$ / $\mathrm{ml}$, NS at $p=0.278$ ). The combination of the three pathogens further stimulated IL-6 release to $4466.6 \mathrm{pg} /$ $\mathrm{ml}$, greater than any individual strain alone (Fig. 2a), significantly higher than $A$. actinomycetemcomitans alone $(p<0.0001)$ and $F$. nucleatum alone $(p=0.0015)$. The combination did not further increase IL-8 release (6645.7 pg/ml) beyond that of $P$. gingivalis alone (Fig. 2b). Despite the ability to adhere to the fibroblasts, S. salivarius K12 or M18 did not induce an IL-6 or an IL-8 response (Fig. 2a, b; NS from control).

Using the same in vitro model system, $S$. salivarius K12 or M18 were applied either simultaneously to the fibroblasts with $P$. gingivalis, $A$. actinomycetemcomitans, $F$. nucleatum (Fig. 3a, b) or were preincubated with the gingival fibroblasts $30 \mathrm{~min}$ prior to being challenged by the pathogens (Fig. 3c, d). When added simultaneously, S. salivarius M18 was able to significantly decrease IL-6 production induced by $P$. gingivalis (Fig. 3a; $p=0.0012$ ). Both $S$. salivarius $\mathrm{K} 12$ and M18 were able to significantly decrease the production of IL- 6 induced by the combination of all three pathogens (Fig. 3a; $p<0.0001$ ). Similarly, both $S$. salivarius strains $\mathrm{K} 12$ and M18 inhibited the production of IL-8 (Fig. $3 \mathrm{~b})$ induced by $P$. gingivalis $(p<0.001)$, F. nucleatum ( $p=0.0059, p=0.0021$, respectively), and the combination of the three pathogens $(p<0.001)$. Although not all decreases were significant, coadministration of either $S$. salivarius K12 or M18 with any of the pathogens demonstrated a minimum inhibition of $34.1 \%$ for IL-6 and $61.5 \%$ for IL-8 (Additional file 3: Table S1).

Furthermore, when added as a pre-treatment, S. salivarius M18 was able to significantly decrease IL-6 secretion induced by $P$. gingivalis alone (Fig. 3c; $p=0.0012$ ). Both $S$. salivarius $\mathrm{K} 12$ and M18 were able to significantly inhibit IL- 6 induction by the combination of all three pathogens by $60.0 \%$ and $80.7 \%$, respectively (Fig. $3 c ; p<0.001$; Additional file 3: Table S1). Similarly, both K12 and M18 were able to significantly inhibit IL-8 induced by $P$. gingivalis (Fig. 3d; $p<0.001)$ and F. nucleatum $(p=0.0027, p=0.0013)$ and the combination of all three pathogens $(p<0.001)$. In all samples tested, S. salivarius K12 and M18 inhibited cytokine release by gingival fibroblasts with a minimum inhibition of $30 \%$ and $63.2 \%$ for IL- 6 and IL-8, respectively. Importantly, under no circumstances did the addition of the S. salivarius K12 or M18 increase the production of IL- 6 or IL- 8 from pathogen stimulated fibroblasts.

\section{Determination of anti-inflammatory factor}

It was determined prior that neither $S$. salivarius K12 nor M18 were able to directly or indirectly (deferred antagonism) inhibit pathogen growth, and therefore, another mechanism of action must exist to account for the reduction in IL-6 and IL-8 response of gingival fibroblasts induced by these pathogens. Focussing on IL-8 release induced by F. nucleatum, different $S$. salivarius $\mathrm{K} 12$ fractions were examined to elucidate the factor responsible. Figure 4 demonstrates that, as expected, IL-8 release was inhibited by S. salivarius K12 when induced by $F$. nucleatum. Surprisingly, S. salivarius K12 filter sterilized whole bacterial supernatant did not

(See figure on next page.)

Fig. 2 Stimulation of cytokine production from human gingival fibroblasts. IL-6 (a) and IL-8 (b) release by primary human gingival fibroblasts induced by 8-h co-incubation with P. gingivalis (PG); A. actinomycetemcomitans (AA); F. nucleatum (FN); S. salivarius K12 (K12); or S. salivarius M18 (M18). Samples were analysed using a one-way ANOVA with Dunnett's multiple comparison test as compared to control $\left({ }^{*} p<0.05\right.$, ${ }^{* *} p<0.01$, ${ }^{* * *} p<0.001$ compared to control). Error bars represent \pm standard error of the mean 


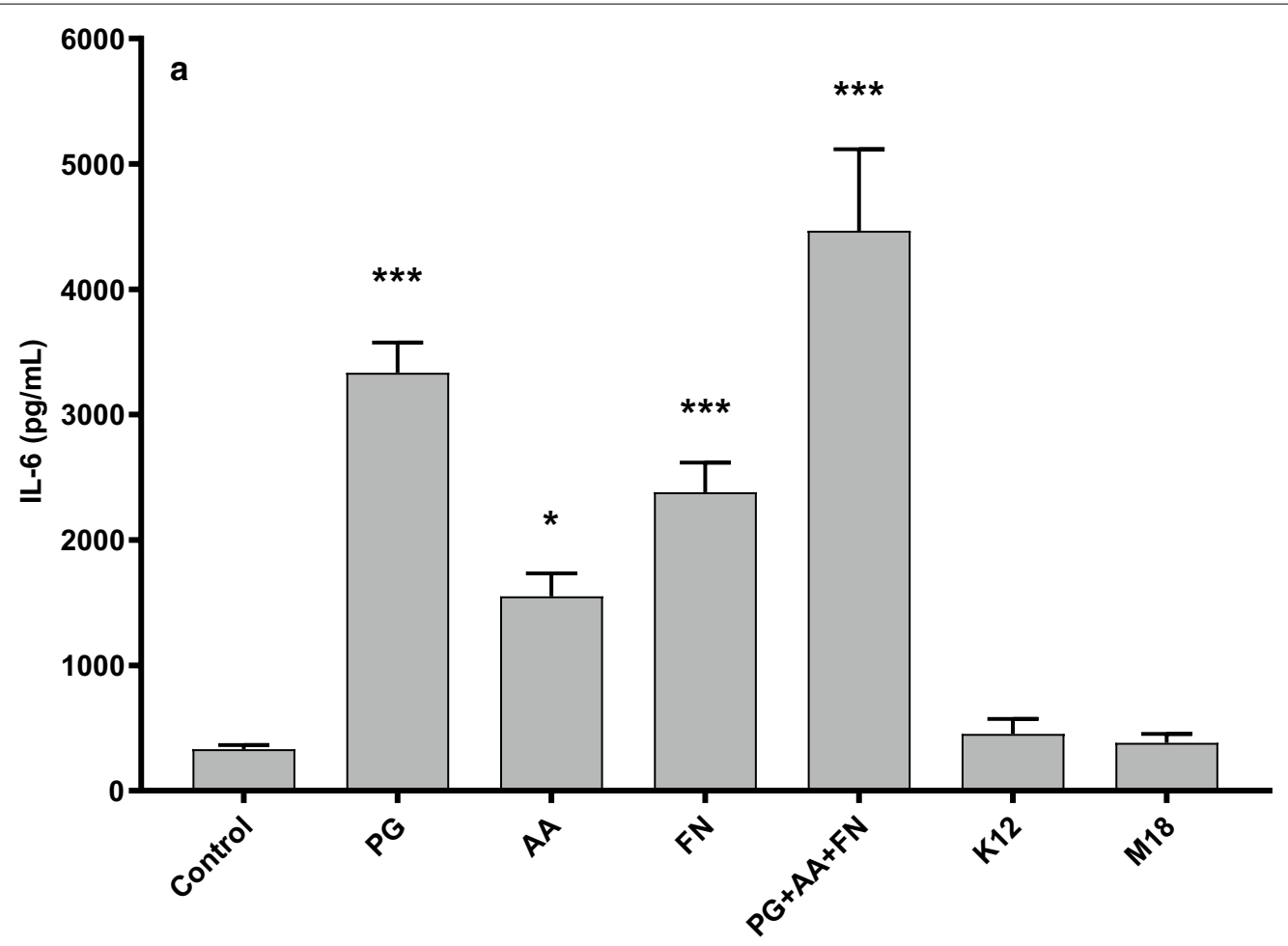

Bacteria

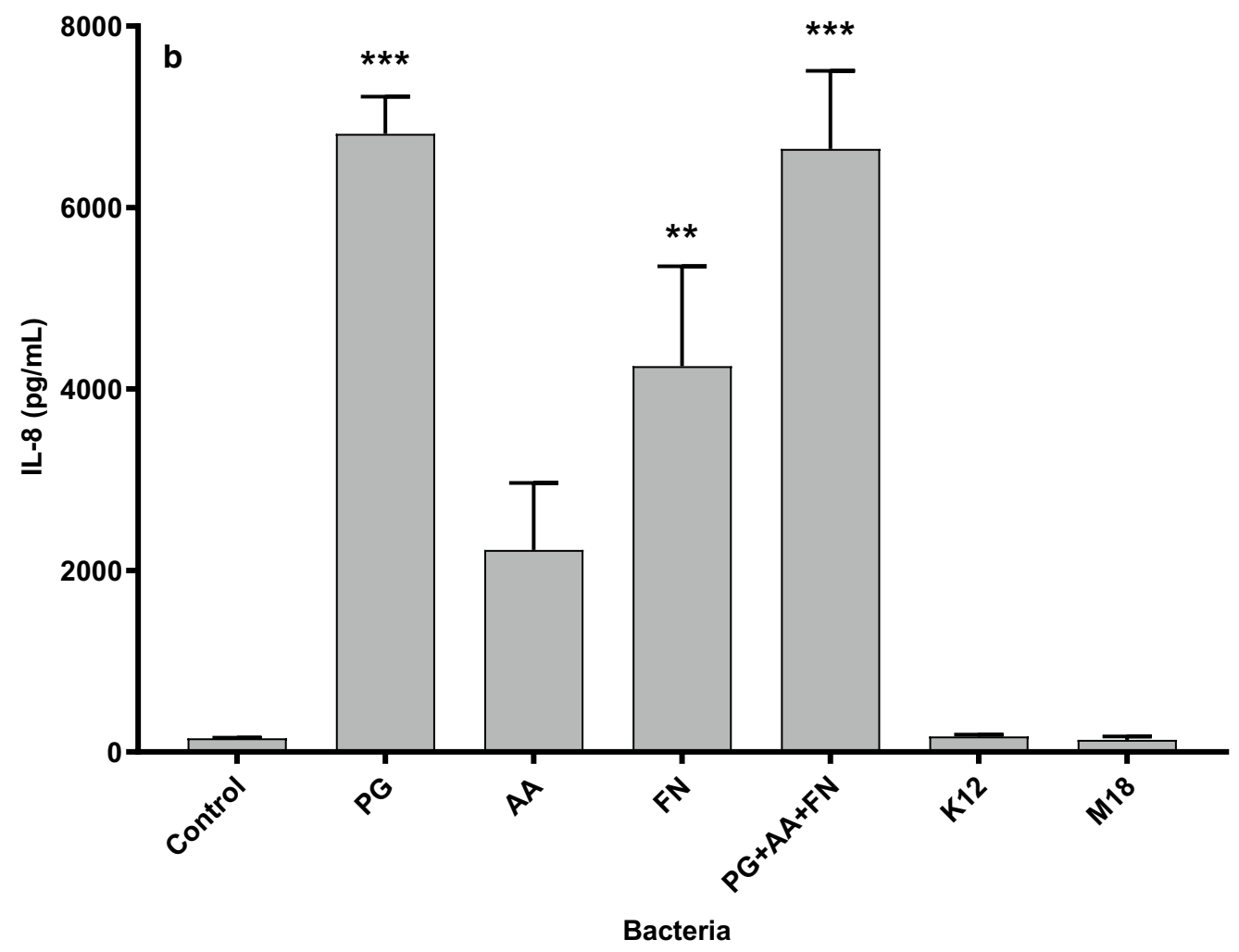



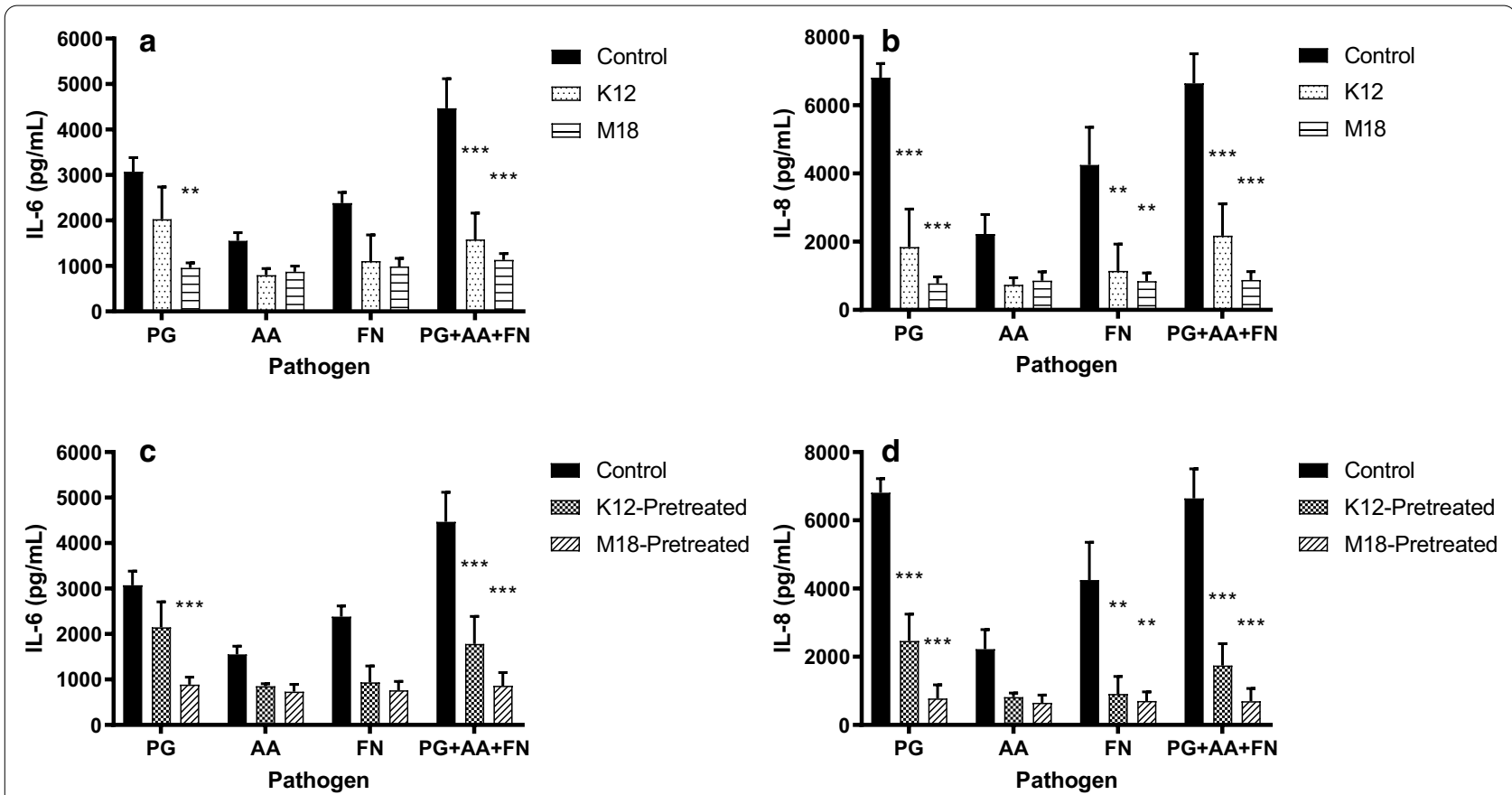

Fig. 3 S. salivarius reduction of pathogen stimulated cytokine release. IL-6 (a) and IL-8 (b) release from primary human gingival fibroblasts induced by P. gingivalis (PG); A. actinomycetemcomitans (AA); F. nucleatum (FN) when co-incubated with S. salivarius K12 (K12) or M18 (M18). IL-6 (c) and IL-8 (d) release from gingival fibroblasts induced by the oral pathogens when S. salivarius K12 (K12-Pretreated) or M18 (M18-Pretreated) were added as a pre-treatment to the fibroblasts 30 min prior to pathogen challenge. Samples were analysed using a two-way ANOVA with Tukey's multiple comparison test within each pathogen group $\left({ }^{* *} p<0.01,{ }^{* *} p<0.001\right)$. Error bars represent \pm standard error of the mean

prevent IL-8 release; however, when the supernatant was fractionated, the smaller size fraction containing $<10 \mathrm{kDa}$ metabolites was able to significantly inhibit IL-8 release $(p=0.0111)$. This is most likely due to a concentration of the causative agent during the fractionation as to why whole supernatant did not have the same effect. To determine if $S$. salivarius produces the compound when on a solid surface, it was grown on agar plates and crudely lysed through a freeze/thaw process that is known to release the intracellular components into a concentrated fraction that can be easily isolated. The freeze/thaw fraction (FT Extract) significantly inhibited IL-8 release (Fig. 4; $p=0.0126$ ). It was also confirmed the agent is heat stable and still active after being treated at $80^{\circ} \mathrm{C}$ for $10 \mathrm{~min}(p=0.0186)$; however, it was inactivated when subjected to a trypsin digest. Therefore, it can be concluded that the agent responsible is a small molecule, less than $10 \mathrm{kDa}$ in size, heat stable and proteinaceous in nature, secreted in small amounts but not anti-microbial to the pathogens tested based on direct and deferred antagonism assays (Table 2).

\section{Effects of probiotic gum on the healthy salivary microbiome}

To examine the effect a probiotic gum containing S. salivarius $\mathrm{K} 12$ would have on a healthy microbiome as well as inflammatory markers, a human study consisting of nineteen healthy volunteers was conducted. The treatment regimen is described in Additional file 1: Figure S1. Samples were collected at baseline, $4 \mathrm{~h}, 24 \mathrm{~h}, 7$ days and 14 days.

Saliva samples were subjected to $16 \mathrm{~S}$ rRNA gene sequencing via the Illumina MiSeq platform. After filtering and clustering sequenced reads at $97 \%$ identity, there were 476 OTUs with $>0.01 \%$ total relative abundance in the saliva samples collected from test subjects. A total number of 2,774,309 sequenced reads were included for analysis, with a median of $29,779 \pm 13,630$ reads per sample. These OTUs were further clustered by taxonomic lineage into 38 family groups of at least $0.05 \%$ relative abundance across all samples. Figure 5 shows the most abundant taxonomic families detected at $>10 \%$ of total classified reads were: Porphyromonadaceae (17.95\%), Pasteurellaceae (15.97\%), Prevotellaceae (15.85\%), and Veillonellaceae (11.22\%). Using PCoA (Fig. 6), the samples did not separate by group (probiotic versus control) in examination of the first 3 components $(81.01 \%$ of the total variance in the data). However, there is a distinct shift in the first component over time with many of the 7-day and 14-day samples differentiating from the earlier timepoints (Fig. 6, bottom row). This differentiation 


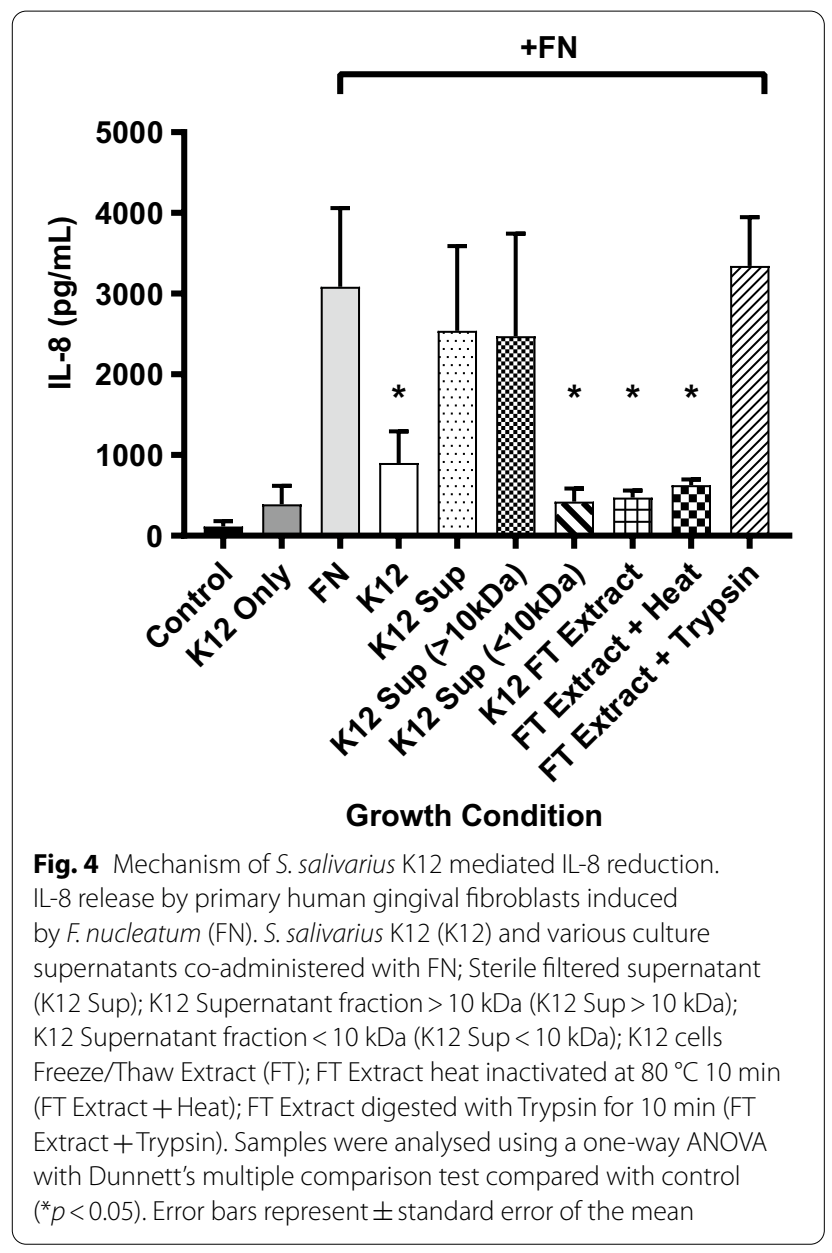

was also independent of group (probiotic versus control). To further examine the apparent time-dependent change in microbiota, the weighted UniFrac distance of all timepoints from individuals in both treatment groups compared to their baseline sample before treatment were plotted (Fig. 7). The median weighted UniFrac distance increased over treatment time indicating a shift in the microbiota. Notably, a subset of the samples at 7 days and 14 days were very distinct from the others.

In order to test if there were any differential taxonomic abundances between groups, a compositional data analysis framework was required and the ALDEx2 toolset was employed to test for significant taxonomic difference between groups at the family level. There were no differences (Benjamini-Hochberg adjusted $p>0.01$ ) between the probiotic and control groups at baseline or study endpoint (14 days), nor between these groups at any of the other sample collection timepoints. Therefore, the treatment groups were pooled to test for differences at end of study (14 days) compared to baseline. There were four family-level taxonomic groups with a relative increase in relative abundance (Table 4), and three with a relative decrease in relative abundance (Benjamini-Hochberg adjusted $p<0.01$ and effect size $\geq 1.5$ ). Examination of the OTUs in the family groups by BLAST to the HOMDB revealed that most of the OTU sequences in Erysipelotrichaceae were similar ( $>80 \%$ sequence identity) to Erysipelothrix tonsillarum (HOT_484) or Solobacterium moorei (HOT_678).

\section{Changes in pro-inflammatory cytokine levels}

Concentrations of four pro-inflammatory cytokines (IL-1 $\beta$, IL-6, IL-8 and TNF- $\alpha$ ) linked with periodontal disease were measured in the collected saliva of nine subjects in the probiotic gum group at each timepoint. These were all healthy individuals with no overt oral disease; however, each participant had some degree of these inflammatory cytokines present in their saliva (Fig. 8). None of the cytokines tested at any of the time points were significantly different from the baseline control (NS from baseline). On average, there was $27.27 \mathrm{pg} / \mathrm{ml}$ IL-1 $\beta, 8.32 \mathrm{pg} / \mathrm{ml} \mathrm{IL-6,} 426.72 \mathrm{pg} / \mathrm{ml} \mathrm{IL}-8$, and $3.27 \mathrm{pg} /$ $\mathrm{ml}$ TNF- $\alpha$. To remove participant variation, each subject was individually analysed, but there were no statistically significant differences in cytokine profile observed (Data not shown).

\section{Discussion}

The ability for $S$. salivarius $\mathrm{K} 12$ and M18 to directly inhibit the growth of oral pathogens is well documented. The most notable mechanism of action has been attributed to megaplasmids pSsal-K12 and pSsal-M18 encoded by S. salivarius K12 and M18, respectively. These megaplasmids encode for many bacteriocins like salivaricin A2 and salivaricin B [20]. Interestingly, neither S. salivarius K12 nor M18 were able to directly inhibit the growth of the oral pathogens tested through direct- and deferredantagonism assays, indicating the inhibition of immune activation was not linked to bacteriocin killing target organisms. This study demonstrated that $S$. salivarius K12 and M18 could interact with other microbes known to cause disease in the oral cavity and influence pathogen-stimulated production of inflammatory mediators from primary human gingival fibroblasts.

It was shown that $S$. salivarius K12 and M18 were both able to adhere to gingival fibroblasts better than another well-known probiotic bacterium, $L$ reuteri $\mathrm{RC}-14$. It is possible that this adherence may compete with oral pathogens to locate suitable binding-sites. Manning et al. [30] demonstrated that $S$. salivarius K12 and M18 were able to prevent pneumococcal adherence to pharyngeal epithelial cells through direct competition for pneumococcal binding sites. Interestingly, both S. salivarius K12 and M18 were able to directly inhibit pneumococcal growth 


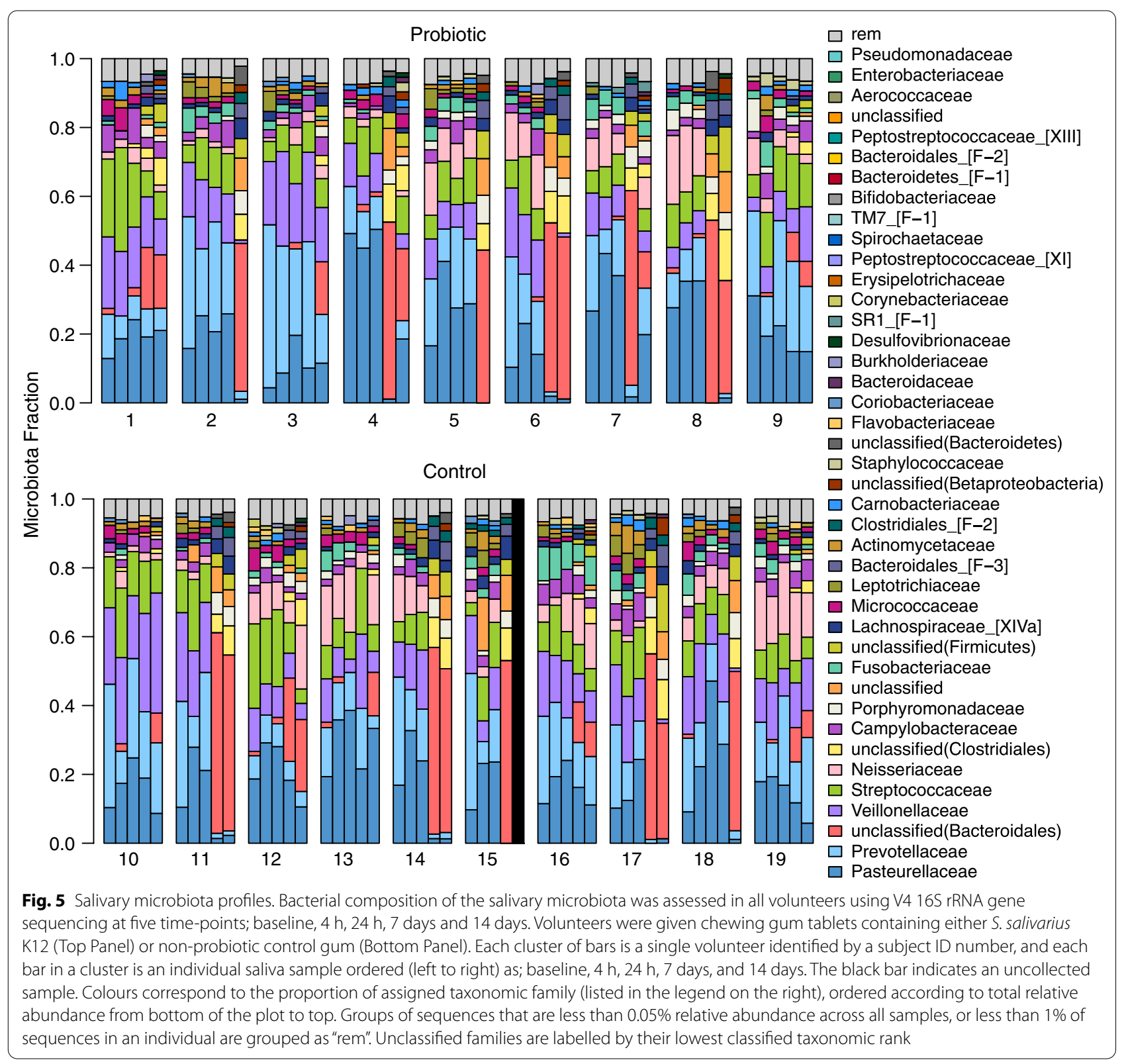

on solid media but this mechanism was not required to prevent pneumococcal adherence. The current study did not determine pathogen binding to the gingival fibroblasts and if S. salivarius K12 or M18 prevented this from occurring. As the active compound was secreted into the supernatant and rendered ineffective upon trypsin treatment, it can be surmised this would not have been the major mechanism of action.

Many species belonging to Streptococcus have documented anti-inflammatory properties. This study demonstrated that both $S$. salivarius K12 and M18 were unable to elicit an IL-6 or an IL-8 response from primary human gingival fibroblasts despite being able to adhere to this tissue well. Moreover, both strains were able to inhibit the IL-6 and IL-8 release induced by three oral pathogens, $P$. gingivalis, A. actinomycetemcomitans, and $F$. nucleatum individually or used in combination. This inhibition occurred whether that strains were co-administered with the pathogens or supplied prior to pathogen challenge. The causative agent was further investigated and was identified to be a small molecule, $<10 \mathrm{kDa}$ in size, heat stable and proteinaceous. This extract was able to inhibit IL-8 release induced by $F$. nucleatum similar to that of adding S. salivarius K12 simultaneously. Therefore, it is 


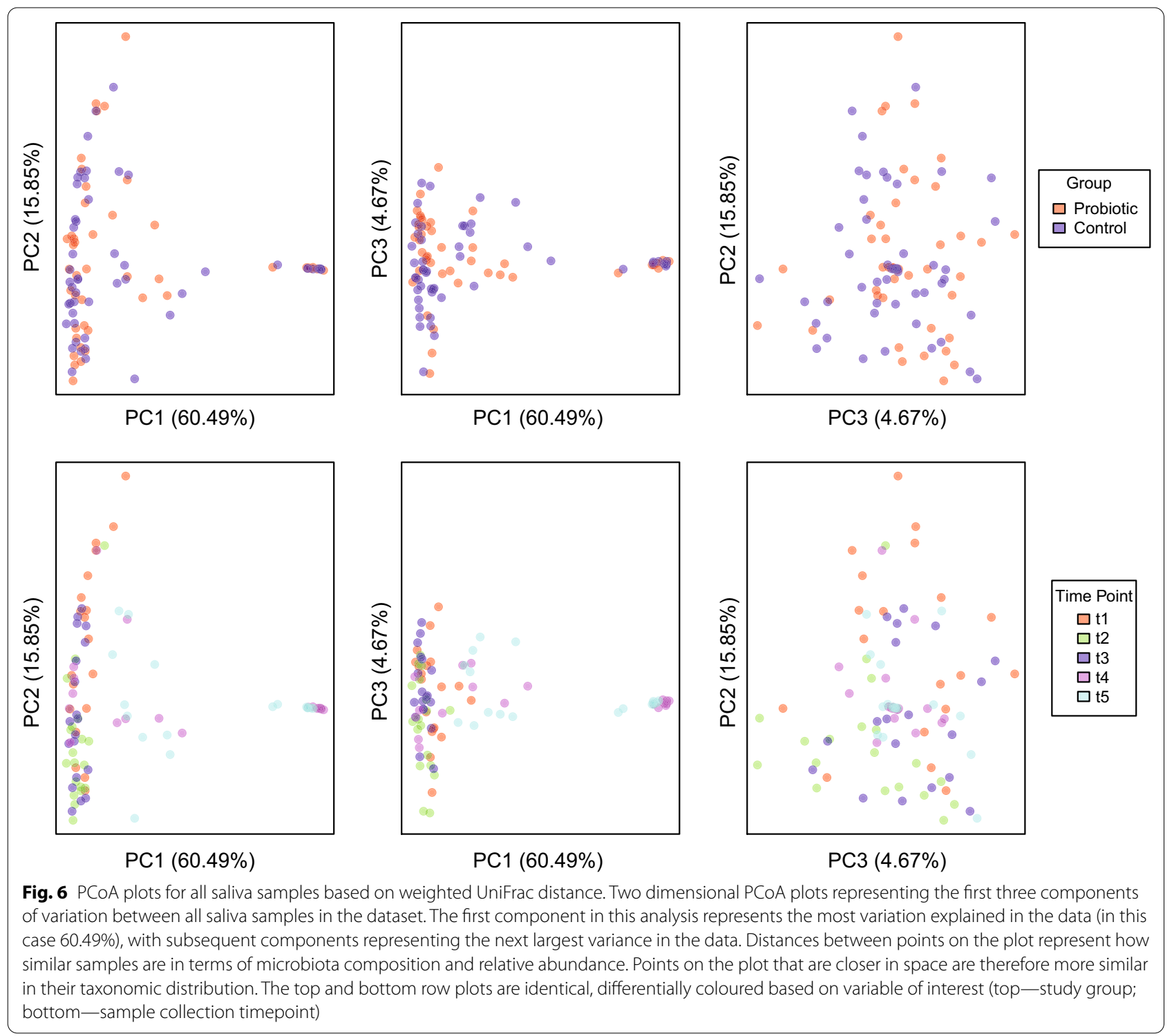

believed that the mechanism of action does not target the bacterium to inhibit pathogenesis but must target the host cells to maintain immune homeostasis. These results correlate well with previous studies showing the anti-inflammatory effect of other S. salivarius and S. vestibularis strains. Kaci et al. [31, 32] have demonstrated that strains of $S$. salivarius inhibited TNF- $\alpha$ activation of the NFK-B inflammatory response of stimulated intestinal epithelial cells, and intra-gastric administration of a live $S$. salivarius significantly inhibited inflammation in mouse models of moderate and severe colitis [31]. The inhibition of NFK-B activation was also observed using culture supernatants of $S$. salivarius and $S$. vestibularis in an NFK-B reporter system in the HT-29 cell line [32]. It was determined a small molecule $<3 \mathrm{kDa}$ in size was responsible for the inhibition of TNF- $\alpha$, IL- $1 \beta$ and IL- 8 [32]. It is likely the effector identified in the current study was similar to the one isolated by Kaci et al. [32]. Our study focused on S. salivarius; however, others have also demonstrated similar decreases in IL-8 release by $S$. mitis and $S$. sanguinis $[33,34]$ indicating this may be a global mechanism associated with many species of beneficial Streptococcus.

Due to the broad range of anti-microbial activity combined with anti-inflammatory properties, and its GRASstatus, probiotic formulations containing S. salivarius for different applications are becoming more widespread. For many years, the simple presence or increased relative abundance of certain bacterial species was believed to be the driving force behind many oral diseases. Streptococcus 


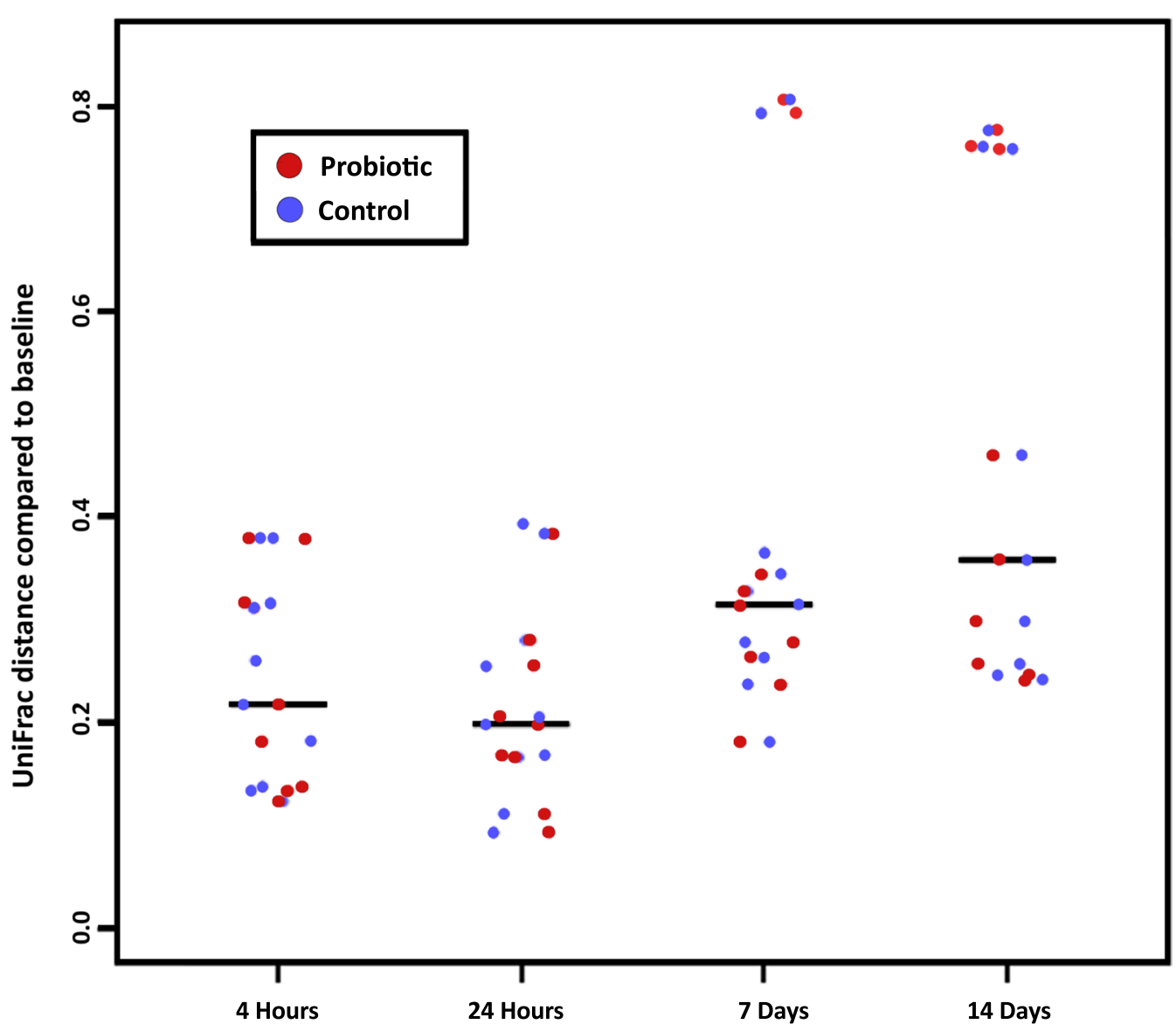

Fig. 7 Change in $\beta$-diversity measured by weighted UniFrac over time. Weighted UniFrac distance of each saliva microbiota sample compared to that individual's baseline sample at $4 \mathrm{~h}, 24 \mathrm{~h}, 7$ days, and 14 days. A value of 0 would represent identical microbiota composition between samples, with a value of 1 representing maximal microbiota differences. Sample points are coloured by study group (probiotic —red; control—blue). Lines represent the median UniFrac distance of a given timepoint. Microbiota compositions change over time (regardless of study group), with a subset of individuals changing drastically at 7 and 14 days

Table 4 Taxonomic groups with significant changes in relative abundance

\begin{tabular}{lll}
\hline Family-level taxonomic group & Wt-BH $^{\dagger}$ & Effect size $^{\ddagger}$ \\
\hline Relative increase & & $1.85 \mathrm{E}-08$ \\
Firmicutes; Erysipelotrichia; Erysipelotrichales; Erysipelotrichaceae & $4.48 \mathrm{E}-08$ & 2.04 \\
Bacteroidetes; Bacteroidia; Bacteroidales; Porphyromonadaceae2 & $5.25 \mathrm{E}-06$ & 1.87 \\
Bacteroidetes; Bacteroidia; Bacteroidales; Bacteroidaceae & $6.86 \mathrm{E}-07$ & 1.57 \\
Bacteroidetes; Bacteroidia; Bacteroidales; Porphyromonadaceae & & 1.51 \\
Relative decrease & $1.39 \mathrm{E}-05$ & -1.77 \\
Fusobacteria; Fusobacteria; Fusobacteriales; Leptotrichiaceae & $1.74 \mathrm{E}-05$ & -1.61 \\
Actinobacteria; Actinobacteria; Actinomycetales; Actinomycetaceae & $1.34 \mathrm{E}-05$ & -1.51 \\
Bacteroidetes; Bacteroidia; Bacteroidales; Prevotellaceae & &
\end{tabular}

${ }^{\dagger}$ Corrected $\mathrm{p}$-value from a paired Welch's t-test using Benjamini-Hochberg procedure [33]

${ }^{\ddagger}$ The median effect size as estimated by ALDEx2 


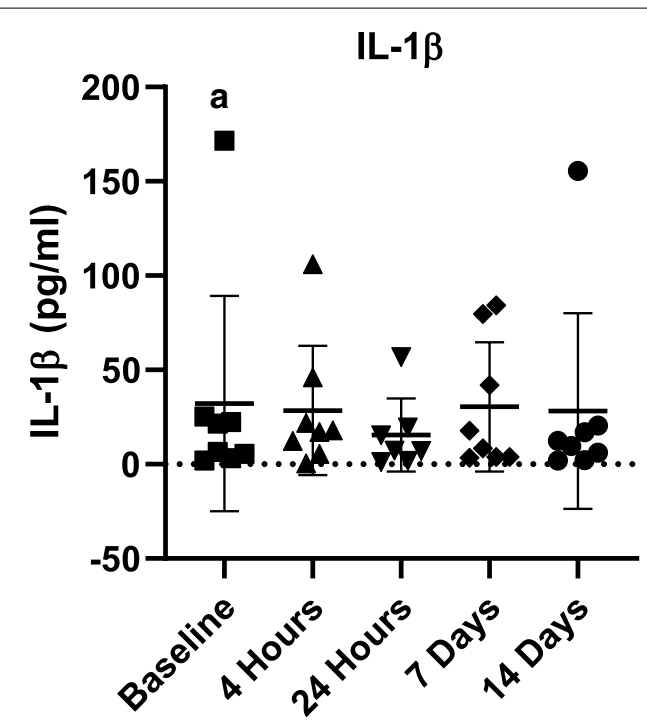

IL-8

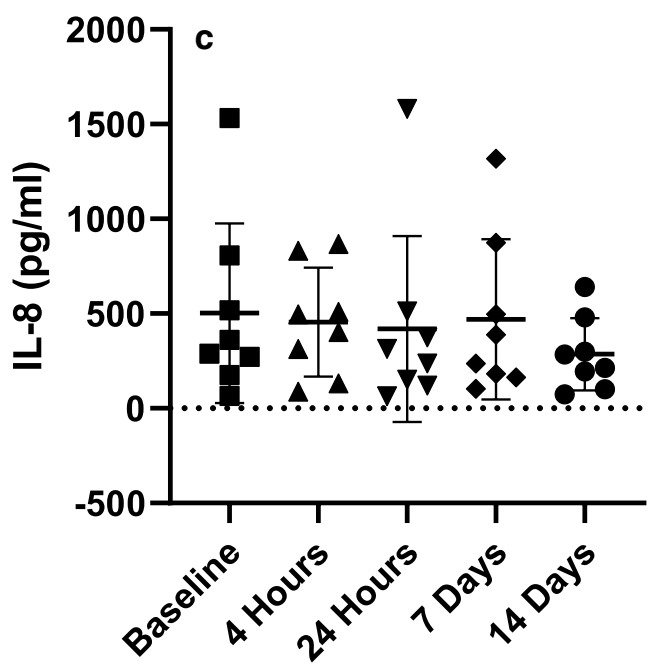

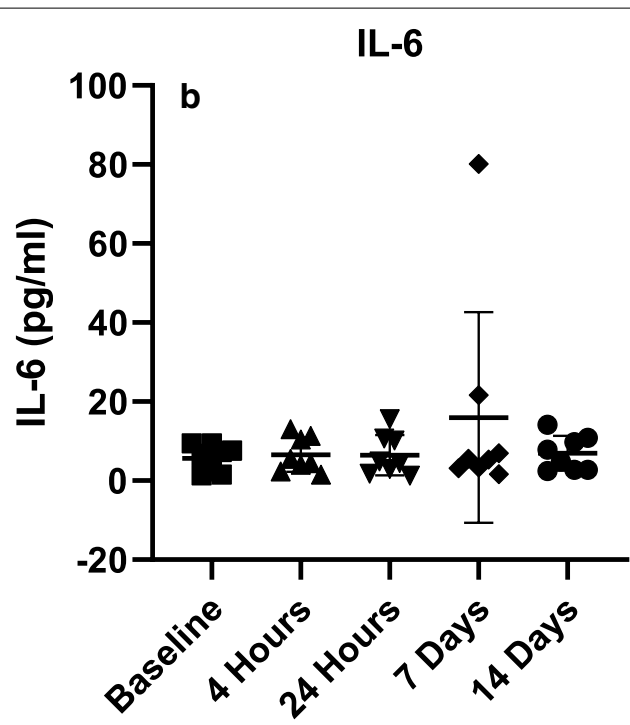

TNF- $\alpha$

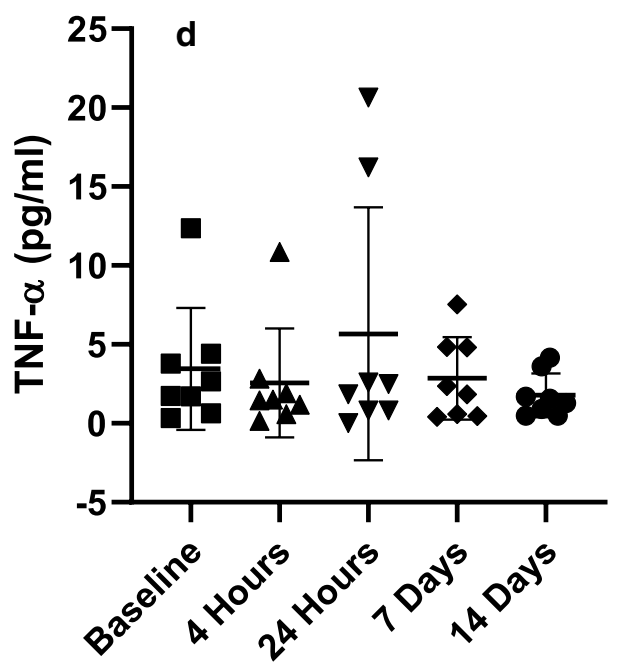

Fig. 8 Salivary levels of pro-inflammatory cytokines of volunteers chewing probiotic tablets. Concentration ( $\mathrm{pg} / \mathrm{mL})$ of IL-1 $\beta$ (a); IL-6 (b); IL-8 (c); TNF-a (d) in saliva samples collected from healthy volunteers chewing the probiotic gum at baseline, 4 h, 24 h, 7 days and 14 days. Cytokine levels for each sample were determined individually with the mean concentration for all individuals shown. Samples were analysed using a one-way repeated-measures ANOVA with Tukey's multiple comparison test. No significant differences were observed. Error bars represent \pm standard error of the mean

mutans was long presumed to be the primary etiological agent of dental caries [35]. In other studies, P. gingivalis, Tannerella forsythia and Treponema denticola (categorized together as the "red complex") were reported to be closely linked with periodontal disease [36]. However, studies using high throughput sequencing techniques have shown that these assumptions are over-simplistic, with diseases often being polymicrobial in nature [37, 38 , and varying in the microbes present between individuals, with different bacteria causing the same clinical manifestation [38]. Furthermore, not all microorganisms have a negative impact on health as a vast range of species including members of Pasteurellaceae and Prevotellaceae are common constituents of both a healthy and diseased oral cavity $[39,40]$. Therefore, it is important to ensure that a product containing S. salivarius designed for the oral cavity does not negatively impact neither the natural microbiome present nor the homeostatic inflammatory environment. 
The application of probiotic gum on a daily-dose regimen for seven days followed by a further 7-day washout period did not modify the microbiota profiles of the healthy volunteers, as has been shown with probiotic yogurt and the gut microbiota [41]. By day 14, there was a shift in microbiota profile of few participants; however, this shift was irrespective of whether the person was administering the probiotic or on the placebo control. This was surprising because it suggests that regular gum use may impact the salivary microbiota in a proportion of the population, which is in contrast to Takeuchi et al.[42] and Söderling et al. [43] that both demonstrated no change in microbiota with regular gum use; however, the populations studied were exclusively men and children, respectively. Narrowing the study design to these specific groups may attribute to the reason no significant observations were observed but further studies would be required.

Addition consumption of S. salivarius K12 in the probiotic gum group did not increase the relative proportion of Streptococcaceae compared to the control group. As $S$. salivarius is the predominant commensal Streptococcus in the oral cavity [6], it is reasonable to presume the population of Streptococcaceae measured was mostly $S$. salivarius. Also, the additional consumption of $S$. salivarius $\mathrm{K} 12$ did not alter the natural immune balance in the mouth, demonstrating the potential for this therapy to be helpful without detriment to the native environment.

S. salivarius is often located on the dorsal surface of the tongue, and therefore would not be in high abundance in sub-gingival sites, the location where pathogens mainly cause inflammation leading to disease. Fortunately, the effector identified in this study would be able to gain access to these sites if released into saliva.

\section{Conclusion}

This study demonstrated that S. salivarius K12 and M18 were able to produce a proteinaceous small molecule capable of inhibiting IL-6 and IL-8 activation of primary human gingival fibroblasts by periodontal disease pathogens. However, this molecule was not a bacteriocin and was not capable of inhibiting the growth of these pathogens. The study also demonstrated that co-administration of the effector and pathogen is not necessary and S. salivarius can be applied prior to pathogen exposure. This administration does not alter the native salivary microbiota nor stimulate an immune response. This shows $S$. salivarius would warrant further study using a population predisposed to periodontal disease.

\section{Abbreviations}

CBA: Columbia blood agar; CFUs: Colony forming units; MEM: Minimum essential medium; OD 600 : Optical density measure at $600 \mathrm{~nm}$; OTUs: Operational taxonomic units; PBS: Phosphate-buffered saline; PCOA: Principal component analysis.

\section{Supplementary Information}

The online version contains supplementary material available at https://doi. org/10.1186/s12903-021-01606-z.

\section{Additional file 1: Figure S1. Chewing Gum Study Design. Figure S1 demonstrates an overview of the design for the chewing gum study. Participants provided samples at Baseline (Day 1), 24h (Day 2), 7 days (Day 8) and after a 7-day washout period (Day 15).}

Additional file 2: Figure S2. Bacterial attachment to primary human gingival fibroblasts. Bacterial attachment to primary human gingival fibroblasts in vitro following 8 hours co- incubation. S. salivarius K12 (K12); S. salivarius M18 (M18); L. reuteri RC-14; S. mutans ATCC25175. Assay was carried out in triplet on three separate occasions. Samples were analysed using a one-way ANOVA with Dunnett's multiple comparison test with $\mathrm{K} 12$ as the control ( ${ }^{*} \mathrm{p}<0.05$ compared to K12 attachment). Error bars represent \pm standard error of the mean. Figure $\$ 2$ demonstrates the level of attachment of a common probiotic Lactobacillus reuteri RC-14 showing S. salivarius $\mathrm{K} 12$ and $\mathrm{M} 18$ have much higher levels of attachment.

Additional file 3: Table S1. Percent decrease of IL-6 and IL-8 cytokine response when primary gingival fibroblasts are stimulated with oral pathogens and either S. salivarius K12 or M18 added simultaneous or as a pre-treatment. Percent decrease calculated based on respective oralpathogen alone.

\section{Acknowledgements}

S. salivarius K12 and M18, C. albicans TIMM 1768, and the nine standard indicator strains (11 to 19) were kindly provided from the laboratory collection of Dr J. R. Tagg (University of Otago, Dunedin, New Zealand). We thank Prairies Natural for supplying the Cultured Care K12 probiotic chewing gum.

\section{Authors' contributions}

Experiments were designed and conceived by KWM, PAC, GR and JPB. Experiments were performed by KWM, analysed by KWM, RMC and JMM. Figures and tables were created by KWM, RMC and JMM. Manuscript was drafted by KWM, RMC and JPB and critically reviewed by KWM, RMC, JMM, PAC, GR and JPB. All authors have read and approved the final manuscript.

\section{Funding}

This research was partly funded by the W. Garfield Weston Foundation to JPB and the Canadian Institutes of Health Research (CIHR) Frederick Banting and Charles Best Canada Graduate Scholarship and the Ontario Graduate Scholarship to KWM. None of the funding bodies played any role in the study design, collection, analysis, data interpretation, or in the writing of the manuscript.

\section{Availability of data and materials}

Data for the current study is available upon request to the corresponding author. Parts of this manuscript contain data present in KWM thesis, freely available at http://ir.lib.uwo.ca/etd/2816.

\section{Declarations}

\section{Ethics approval and consent to participate}

The study was approved by the Health Sciences Research Ethics Board at The University of Western Ontario (REB 104641) and the Clinical Research Impact Committee at the Lawson Health Research Institute (R-13-523). Letters of consent were signed by all participants.

Consent for publication

Not applicable. 


\section{Competing interests}

The authors do not have any competing interests to declare.

\section{Author details}

'Department of Microbiology and Immunology, Schulich School of Medicine and Dentistry, University of Western Ontario, London, ON, Canada. ${ }^{2}$ Canadian Centre for Human Microbiome and Probiotic Research, Lawson Health Research Institute, London, ON, Canada. ${ }^{3}$ Department of Biochemistry, Schulich School of Medicine and Dentistry, University of Western Ontario, London, ON, Canada. ${ }^{4}$ School of Health Sciences, Fanshawe College, London, ON, Canada. ${ }^{5}$ Department of Surgery, Division of Urology, Schulich School of Medicine and Dentistry, University of Western Ontario, London, ON, Canada.

\section{Received: 23 June 2020 Accepted: 29 April 2021}

Published online: 07 May 2021

\section{References}

1. Eke PI, Dye BA, Wei L, Thornton-Evans GO, Genco RJ, Cdc Periodontal Disease Surveillance workgroup: James Beck GDRP. Prevalence of periodontitis in adults in the United States: 2009 and 2010. J Dent Res. 2012;91(10):914-20.

2. Liu B, Faller LL, Klitgord N, Mazumdar V, Ghodsi M, Sommer DD, et al. Deep sequencing of the oral microbiome reveals signatures of periodontal disease. PLoS ONE. 2012;7(6):e37919.

3. Haffajee AD, Socransky SS. Microbial etiological agents of destructive periodontal diseases. Periodontol. 2000;1994(5):78-111.

4. Okada H, Murakami S. Cytokine expression in periodontal health and disease. Crit Rev Oral Biol Med. 1998;9(3):248-66.

5. Petersen PE. World Health Organization global policy for improvement of oral health-World Health Assembly 2007. Int Dent J. 2008;58(3):115-21.

6. Wescombe PA, Heng NC, Burton JP, Chilcott CN, Tagg JR. Streptococcal bacteriocins and the case for Streptococcus salivarius as model oral probiotics. Future Microbiol. 2009;4(7):819-35.

7. Roslund MI, Puhakka R, Grönroos M, Nurminen N, Oikarinen S, Gazali AM, et al. Biodiversity intervention enhances immune regulation and healthassociated commensal microbiota among daycare children. Sci Adv. 2020;6(42):eaba2578.

8. Karczewski J, Troost FJ, Konings I, Dekker J, Kleerebezem M, Brummer R-JM, et al. Regulation of human epithelial tight junction proteins by Lactobacillus plantarum in vivo and protective effects on the epithelial barrier. Am J Physiol Gastrointest Liver Physiol. 2010;298(6):G851-9.

9. Qin $H$, Zhang Z, Hang $X$, Jiang YL. plantarum prevents enteroinvasive Escherichia coli-induced tight junction proteins changes in intestinal epithelial cells. BMC Microbiol. 2009;9:63.

10. Crittenden RG, Martinez NR, Playne MJ. Synthesis and utilisation of folate by yoghurt starter cultures and probiotic bacteria. Int J Food Microbiol. 2003;80(3):217-22.

11. Morishita T, Tamura N, Makino T, Kudo S. Production of menaquinones by lactic acid bacteria. J Dairy Sci. 1999;82(9):1897-903.

12. Reid G, Younes JA, Van der Mei HC, Gloor GB, Knight R, Busscher HJ. Microbiota restoration: natural and supplemented recovery of human microbial communities. Nat Rev Microbiol. 2011;9(1):27-38.

13. Walker WA. Mechanisms of action of probiotics. Clin Infect Dis. 2008;46(Suppl 2):S87-91 (discussion S144-51).

14. Yan F, Cao H, Cover TL, Whitehead R, Washington MK, Polk DB. Soluble proteins produced by probiotic bacteria regulate intestinal epithelial cell survival and growth. Gastroenterology. 2007;132(2):562-75.

15. Isolauri E, Sütas $Y$, Kankaanpää $P$, Arvilommi H, Salminen S. Probiotics: effects on immunity. Am J Clin Nutr. 2001;73(2 Suppl):444S-S450.

16. Teughels W, Durukan A, Ozcelik O, Pauwels M, Quirynen M, Haytac MC. Clinical and microbiological effects of Lactobacillus reuteri probiotics in the treatment of chronic periodontitis: a randomized placebo-controlled study. J Clin Periodontol. 2013;40(11):1025-35.

17. Shimauchi H, Mayanagi G, Nakaya S, Minamibuchi M, Ito Y, Yamaki K, et al. Improvement of periodontal condition by probiotics with Lactobacillus salivarius WB21: a randomized, double-blind, placebo-controlled study. J Clin Periodontol. 2008;35(10):897-905.
18. Burton JP, Wescombe PA, Cadieux PA, Tagg JR. Beneficial microbes for the oral cavity: time to harness the oral streptococci? Benef Microbes. 2011:2(2):93-101.

19. Wescombe PA, Burton JP, Cadieux PA, Klesse NA, Hyink O, Heng NC, et al. Megaplasmids encode differing combinations of lantibiotics in Streptococcus salivarius. Antonie Van Leeuwenhoek. 2006;90(3):269-80.

20. Hyink O, Wescombe PA, Upton M, Ragland N, Burton JP, Tagg JR. Salivaricin $A 2$ and the novel lantibiotic salivaricin $B$ are encoded at adjacent loci on a 190-kilobase transmissible megaplasmid in the oral probiotic strain Streptococcus salivarius K12. Appl Environ Microbiol. 2007;73(4):1107-13.

21. Heng NC, Haji-Ishak NS, Kalyan A, Wong AY, Lovric M, Bridson JM, et al. Genome sequence of the bacteriocin-producing oral probiotic Streptococcus salivarius strain M18. J Bacteriol. 2011;193(22):6402-3.

22. Burton JP, Chilcott CN, Wescombe PA, Tagg JR. Extended safety data for the oral cavity probiotic Streptococcus salivarius K12. Probiotics Antimicrob Proteins. 2010;2(3):135-44.

23. Burton JP, Cowley S, Simon RR, McKinney J, Wescombe PA, Tagg JR. Evaluation of safety and human tolerance of the oral probiotic Streptococcus salivarius K12: a randomized, placebo-controlled, double-blind study. Food Chem Toxicol Int J Publ Br Ind Biol Res Assoc. 2011;49(9):2356-64

24. Burton JP, Wescombe PA, Moore CJ, Chilcott CN, Tagg JR. Safety assessment of the oral cavity probiotic Streptococcus salivarius K12. Appl Environ Microbiol. 2006;72(4):3050-3.

25. Burton JP, Wescombe PA, Macklaim JM, Chai MH, Macdonald K, Hale JD, et al. Persistence of the oral probiotic Streptococcus salivarius M18 is dose dependent and megaplasmid transfer can augment their bacteriocin production and adhesion characteristics. PLoS ONE. 2013;8(6):e65991.

26. Horz HP, Meinelt A, Houben B, Conrads G. Distribution and persistence of probiotic Streptococcus salivarius K12 in the human oral cavity as determined by real-time quantitative polymerase chain reaction. Oral Microbiol Immunol. 2007:22(2):126-30.

27. Di Pierro F, Adami T, Rapacioli G, Giardini N, Streitberger C. Clinical evaluation of the oral probiotic Streptococcus salivarius K12 in the prevention of recurrent pharyngitis and/or tonsillitis caused by Streptococcus pyogenes in adults. Expert Opin Biol Ther. 2013;13(3):339-43.

28. Di Pierro F, Donato G, Fomia F, Adami T, Careddu D, Cassandro C, et al. Preliminary pediatric clinical evaluation of the oral probiotic Streptococcus salivarius K12 in preventing recurrent pharyngitis and/or tonsillitis caused by Streptococcus pyogenes and recurrent acute otitis media. Int J Gen Med. 2012:5:991-7.

29. Burton JP, Drummond BK, Chilcott CN, Tagg JR, Thomson WM, Hale JD, et al. Influence of the probiotic Streptococcus salivarius strain M18 on indices of dental health in children: a randomized double-blind, placebocontrolled trial. J Med Microbiol. 2013;62(Pt 6):875-84.

30. Manning J, Dunne EM, Wescombe PA, Hale JDF, Mulholland EK, Tagg $J$, et al. Investigation of Streptococcus salivarius-mediated inhibition of pneumococcal adherence to pharyngeal epithelial cells. BMC Microbiol. 2016;16(1):225

31. Kaci G, Goudercourt D, Dennin V, Pot B, Dore J, Ehrlich SD, et al. Antiinflammatory properties of Streptococcus salivarius, a commensal bacterium of the oral cavity and digestive tract. Appl Environ Microbiol. 2014;80(3):928-34.

32. Kaci G, Lakhdari O, Dore J, Ehrlich SD, Renault P, Blottiere HM, et al. Inhibition of the NF-kappaB pathway in human intestinal epithelial cells by commensal Streptococcus salivarius. Appl Environ Microbiol. 2011;77(13):4681-4

33. Cosseau C, Devine DA, Dullaghan E, Gardy JL, Chikatamarla A, Gellatly $\mathrm{S}$, et al. The commensal Streptococcus salivarius K12 downregulates the innate immune responses of human epithelial cells and promotes hostmicrobe homeostasis. Infect Immun. 2008;76(9):4163-75.

34. Sliepen I, Van Damme J, Van Essche M, Loozen G, Quirynen M, Teughels W. Microbial interactions influence inflammatory host cell responses. J Dent Res. 2009;88(11):1026-30.

35. Rosier BT, De Jager M, Zaura E, Krom BP. Historical and contemporary hypotheses on the development of oral diseases: are we there yet? Front Cell Infect Microbiol. 2014;4:92.

36. Socransky SS, Haffajee AD, Cugini MA, Smith C, Kent RL. Microbial complexes in subgingival plaque. J Clin Periodontol. 1998;25(2):134-44.

37. Takahashi N, Nyvad B. The role of bacteria in the caries process: ecological perspectives. J Dent Res. 2011;90(3):294-303. 
38. Schwarzberg K, Le R, Bharti B, Lindsay S, Casaburi G, Salvatore F, et al. The personal human oral microbiome obscures the effects of treatment on periodontal disease. PLoS ONE. 2014;9(1):e86708-e.

39. Zaura E, Keijser BJ, Huse SM, Crielaard W. Defining the healthy "core microbiome" of oral microbial communities. BMC Microbiol. 2009;9:259.

40. Yang F, Zeng X, Ning K, Liu K-L, Lo C-C, Wang W, et al. Saliva microbiomes distinguish caries-active from healthy human populations. ISME J. 2012;6(1):1-10.

41. McNulty NP, Yatsunenko T, Hsiao A, Faith JJ, Muegge BD, Goodman AL, et al. The impact of a consortium of fermented milk strains on the gut microbiome of gnotobiotic mice and monozygotic twins. Sci Transl Med. 2011;3(106):106ra-ra.
42. Takeuchi K, Asakawa M, Hashiba T, Takeshita T, Saeki Y, Yamashita Y. Effects of xylitol-containing chewing gum on the oral microbiota. J Oral Sci. 2018; advpub.

43. Söderling E, EISalhy M, Honkala E, Fontana M, Flannagan S, Eckert G, et al. Effects of short-term xylitol gum chewing on the oral microbiome. Clin Oral Investig. 2015;19(2):237-44.

\section{Publisher's Note}

Springer Nature remains neutral with regard to jurisdictional claims in published maps and institutional affiliations.
Ready to submit your research? Choose BMC and benefit from:

- fast, convenient online submission

- thorough peer review by experienced researchers in your field

- rapid publication on acceptance

- support for research data, including large and complex data types

- gold Open Access which fosters wider collaboration and increased citations

- maximum visibility for your research: over 100M website views per year

At BMC, research is always in progress.

Learn more biomedcentral.com/submissions 